\title{
Creatinine clearance and risk of early mortality in patients undergoing coronary artery bypass grafting
}

\author{
Martin J. Holzmann, MD, ${ }^{\text {a }}$ Staffan Ahnve, MD, PhD, FACC, ${ }^{\text {b }}$ Niklas Hammar, PhD, ${ }^{\text {c,d }}$ Lena Jörgensen, MSc, ${ }^{d}$ \\ Kristina Klerdal, $\mathrm{MSc}^{d}{ }^{d}$ Kenneth Pehrsson, MD, PhD, ${ }^{\mathrm{e}}$ and Torbjörn Ivert, MD, PhDa
}

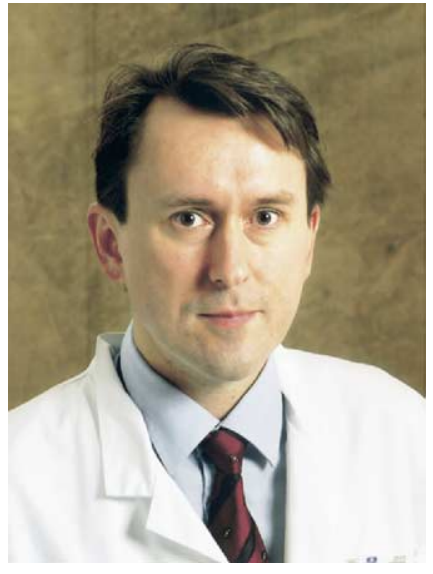

Dr Holzmann

Extra material is available online. 刍
From the Department of Thoracic Surgery, Karolinska University Hospital ${ }^{\text {a }}$; the Department of Preventive Medicine, Stockholm Centre of Public Health ${ }^{\text {b }}$ the Division of Epidemiology, Institute of Environmental Medicine ${ }^{\mathrm{c}}$; the Department of Epidemiology, Stockholm Center of Public Health ${ }^{\mathrm{d}}$; and the Department of Cardiology, Karolinska University Hospitale ${ }^{\mathrm{e}}$, the Karolinska Institute, Stockholm, Sweden.

Financial support was provided by EXPO 95 of the Stockholm County Council and the Ansgarius Foundation.

Received for publication June 10, 2004; revisions received Feb 3, 2005; accepted for publication Feb 28, 2005.

Address for reprints: Martin J. Holzmann, MD, Department of Emergency Medicine, Karolinska University Hospital, 171 76, Stockholm, Sweden (E-mail: martin. holzmann@karolinska.se).

J Thorac Cardiovasc Surg 2005;130:746-52

$0022-5223 / \$ 30.00$

Copyright (c) 2005 by The American Association for Thoracic Surgery

doi:10.1016/j.jtcvs.2005.02.067
Objectives: We sought to evaluate renal function assessed on the basis of calculated creatinine clearance as a predictor of early mortality and postoperative complications in patients undergoing coronary artery bypass grafting and to assess whether calculated creatinine clearance is superior to serum creatinine concentration in predicting early death postoperatively.

Methods: Six thousand seven hundred eleven consecutive patients without dialysisdependent renal insufficiency undergoing a first isolated coronary artery bypass grafting were included. Preoperative serum creatinine concentrations and creatinine clearance calculated by using the Cockroft-Gault formula were related to mortality within 30 days postoperatively.

Results: There were 136 early deaths. After adjustment for age and other confounders in multivariate analyses, moderate (calculated creatinine clearance $30-60 \mathrm{~mL} /$ $\mathrm{min}$ ) and severe (calculated creatinine clearance $<30 \mathrm{~mL} / \mathrm{min}$ ) renal insufficiency predicted early mortality (odds ratio of 2.4 [95\% confidence interval, 1.2-4.8] and odds ratio of 4.8 [95\% confidence interval], 1.6-13.9, respectively) compared with normal (calculated creatinine clearance $\geq 90 \mathrm{~mL} / \mathrm{min}$ ) renal function. The area under the receiver operating characteristic curve for calculated creatinine clearance and serum creatinine concentration was 0.71 and 0.62 , respectively, yielding a difference of $0.08(P=.0004)$. No increased risk of mediastinitis or bleeding was observed in patients with renal insufficiency.

Conclusion: Moderate and severe renal insufficiency independently increase the risk of early death after coronary artery bypass grafting. Our results indicate that calculated creatinine clearance is a better predictor of early mortality postoperatively than serum creatinine concentration.

$\mathrm{P}$ atients with renal insufficiency (RI) have an increased risk of cardiovascular events independent of other risk factors. ${ }^{1,2}$ This is true already for mild RI in both men and women. ${ }^{3-5}$

It is also known that patients with end-stage renal disease who require dialysis have a markedly increased mortality after myocardial infarction (MI), as well as coronary artery bypass grafting (CABG).$^{6-8}$ Several studies have assessed the risk associated with mild or moderate RI in patients undergoing CABG. ${ }^{9-12}$ In these studies renal function has been defined according to levels of serum creatinine and not to calculated creatinine clearance $(\mathrm{Ccr})$. Because serum creatinine concentrations are affected by several factors other than the filtration of creatinine, Ccr will provide a more accurate estimate of renal function. ${ }^{13}$

We hypothesized that patients with impaired renal function would have a higher risk of early mortality and postoperative complications after undergoing CABG than patients with normal renal function. Another purpose was to compare Ccr with 
serum creatinine concentration as a predictor of early mortality after CABG.

\section{Methods \\ Patients}

All patients without dialysis-dependent renal failure who underwent a first CABG without any concurrent intracardiac or vascular procedures at the Karolinska Hospital in Stockholm, Sweden, between 1980 and $1995(\mathrm{n}=6711)$ were included. During this period, 12 patients with end-stage renal failure requiring dialysis underwent $\mathrm{CABG}$ at the same hospital. All patients were operated on during cardiopulmonary bypass. The following information was registered from medical records for all patients: age, sex, height, weight, diabetes mellitus, hypertension, peripheral vascular disease, left ventricular function (LVF), year of operation, left main coronary artery stenosis, number of significantly obstructed coronary arteries, prior stroke, prior MI, unstable angina during the current admission, serum creatinine concentration, dialysis-dependent renal failure, prior cardiac surgery (CABG, valve procedure, or any thoracic vascular surgery), postoperative bleeding, and mediastinitis.

Of 6711 patients included in the study, 6521 (97\%) had complete data on history of MI, weight, height, previous stroke, diabetes mellitus, unstable angina, hypertension, peripheral vascular disease, serum creatinine concentration, left main coronary artery stenosis, and number of significantly obstructed coronary arteries. In 1114 (17\%) patients information on LVF was not available. All patients had complete data on age, sex, and year of operation.

\section{Renal Function}

Serum creatinine concentration was measured at the time of hospital admission. During the whole study period, serum creatinine concentration was analyzed by the same method ${ }^{14}$ and at the same laboratory at the Karolinska Hospital, Stockholm, Sweden. Ccr was calculated by the equation of Cockroft and Gault ${ }^{15}$ as follows for men: $(140-$ Age $) \times($ Weight;kg])/72 $\times($ Serumcreatinine $[\mu \mathrm{mol} / \mathrm{L}] / 88.4)$. In women the value was multiplied by 0.85 . RI was defined according to the guidelines from the National Kidney Foundation. ${ }^{16}$ Normal renal function was defined as a Ccr of 90 $\mathrm{mL} / \mathrm{min}$ or more. Mild, moderate, and severe RI was defined as Ccr values of 60 to $90 \mathrm{~mL} / \mathrm{min}, 30$ to $60 \mathrm{~mL} / \mathrm{min}$, and less than 30 $\mathrm{mL} / \mathrm{min}$, respectively. Ccr could not be calculated in $156(2 \%)$ patients because of missing data on serum creatinine concentration $(n=103)$, weight $(n=13)$, or serum creatinine concentration and weight $(n=40)$.

\section{Definitions}

Patients were defined as having diabetes if they were taking insulin or oral hypoglycemic agents and as having hypertension if they were taking antihypertensive medication. A coronary artery was defined as significantly obstructed if the luminal diameter was narrowed by at least $50 \%$, as assessed visually by the physician performing the coronary angiography. LVF was assessed by using preoperative contrast ventriculography or echocardiography. LVF was categorized as normal, reduced, or severely reduced according to the assessment of the thoracic surgeon or the physician performing the ventriculography or echocardiography. Normal LVF was defined as an ejection fraction of more than $55 \%$ on ventricu- lography or echocardiography, no dilation of the cardiac chambers, and no dyskinetic, hypokinetic, or akinetic segments. A reduced LVF was defined as an ejection fraction of less than $55 \%$ but more than $30 \%$. A severely reduced LVF was defined as a markedly dilated ventricle with akinetic or hypokinetic segments or an estimated ejection fraction of less than $30 \%$. Peripheral vascular disease was defined as a history of exertional claudication, prior revascularization, or both to the legs. The patients were classified as having unstable angina if they were admitted to the hospital because of angina at rest, a new onset, or accelerated angina within 4 weeks of the operation or angina within 2 weeks of an MI. Body mass index (BMI) was calculated by dividing weight in kilograms by the square of height in meters.

Postoperative bleeding was defined as bleeding requiring reoperation within 48 hours after initial departure from the operating room. Mediastinitis was defined as a postoperative deep sternal wound infection requiring antibiotics and the return to the operating room for surgical intervention.

\section{Outcome Data}

Early mortality was defined as deaths occurring within 30 days of the operation. Every person living permanently in Sweden has a unique identification number that was used for record linkage to the national cause-of-death register, where all the deaths in Sweden are registered with essentially a complete coverage. If there was no information on a prior MI in the medical record, 2 registers were used to confirm this, one that contains information on all MIs occurring in the population of Stockholm County between 1972 and 1995 and one with information on all MIs that occurred in Sweden during the period of 1987 through 1995.

\section{Statistical Analysis}

Patient characteristics were compared between groups categorized by calculated Ccr by differences in means or proportions. Continuous variables are presented by using means with 1 standard deviation, and differences in means between patient groups are evaluated by using analyses of variance. A global test of the hypothesis of no differences between the groups compared was performed with a $\chi^{2}$ test for categorical variables and analysis of variance for continuous variables. Early death for patients with reduced Ccr compared with patients with normal Ccr was analyzed by logistic regression. These analyses were performed crude, adjusted for age at operation only, and with multivariate adjustment for potential confounding from other patient characteristics. In the multivariate analyses, variables included in the final model were those with an influence exceeding $10 \%$ on the estimated odds ratio (OR) for $\mathrm{Ccr}$ in relation to the outcome (eg, early mortality). Information about LVF was missing in $17 \%$ of patients, and in this group there was a tendency toward reduced $\mathrm{Ccr}$ and an increased risk of early death. Excluding this group would most likely underestimate the association between Ccr and early mortality. To retain information on the association between Ccr and mortality, we included subjects with missing data on LVF as a separate category in the multivariate analyses. Age and BMI were included as continuous variables, and all other variables were dichotomized. For most variables, the dichotomies represented the presence or absence of the characteristic. Year of operation was subdivided into the following categories: 1980 through 1984, 1985 through 
TABLE 1. Characteristics of 6711 patients undergoing coronary artery bypass grafting from 1980 through 1995 in relation to preoperative creatinine clearance

\begin{tabular}{|c|c|c|c|c|c|c|}
\hline & \multirow{2}{*}{$\begin{array}{c}\text { All } \\
\text { patients* }\end{array}$} & \multicolumn{4}{|c|}{ Creatinine clearance $(\mathrm{mL} / \mathrm{min})$} & \multirow[b]{2}{*}{$P$ value } \\
\hline & & $\geq 90$ & $60-90$ & $30-60$ & $<30$ & \\
\hline No. of patients $(\%)$ & 6711 & $1888(28)$ & 3212 (48) & $1391(21)$ & $64(1)$ & - \\
\hline Age (y) & $61 \pm 9$ & $54 \pm 8$ & $62 \pm 8$ & $69 \pm 7$ & $71 \pm 9$ & $\leq .001$ \\
\hline $\mathrm{BMI}$ & $26 \pm 3$ & $28 \pm 3$ & $26 \pm 3$ & $25 \pm 3$ & $24 \pm 3$ & $\leq .001$ \\
\hline Serum creatinine $(\mu \mathrm{mol} / \mathrm{L})$ & $100 \pm 31$ & $85 \pm 13$ & $99 \pm 16$ & $118 \pm 27$ & $268 \pm 158$ & $\leq .001$ \\
\hline Serum creatinine $(\mathrm{mg} / \mathrm{dL})$ & $1.1 \pm 0.4$ & $1.0 \pm 0.1$ & $1.1 \pm 0.2$ & $1.3 \pm 0.3$ & $3.0 \pm 1.8$ & $\leq .001$ \\
\hline \multicolumn{7}{|l|}{ Year of the operation } \\
\hline 1980-1984 (\%) & $1372(20)$ & $448(24)$ & $667(21)$ & $163(12)$ & $4(6)$ & $\leq .001$ \\
\hline $1985-1989(\%)$ & $1842(27)$ & $486(26)$ & $952(30)$ & $358(26)$ & $14(22)$ & \\
\hline 1990-1995 (\%) & $3497(52)$ & $954(51)$ & $1593(50)$ & $870(63)$ & $46(72)$ & \\
\hline Unstable angina (\%) & $1126(17)$ & $276(15)$ & 486 (15) & $317(23)$ & $25(39)$ & $\leq .001$ \\
\hline Hypertension (\%) & $2011(30)$ & $549(29)$ & $945(29)$ & $450(32)$ & $34(53)$ & $\leq .001$ \\
\hline Previous MI (\%) & $3862(58)$ & $1028(54)$ & $1845(57)$ & $856(62)$ & $49(77)$ & $\leq .001$ \\
\hline Previous stroke (\%) & $390(6)$ & $81(4)$ & $185(6)$ & $113(8)$ & $6(9)$ & $\leq .001$ \\
\hline Peripheral vascular disease $(\%)$ & $451(7)$ & $70(4)$ & $219(7)$ & $139(10)$ & $9(14)$ & $\leq .001$ \\
\hline Diabetes mellitus $(\%)$ & $852(13)$ & $287(15)$ & $365(11)$ & $173(12)$ & $9(14)$ & .001 \\
\hline Insulin treatment $(\%)$ & $298(35)$ & $82(29)$ & $143(39)$ & $67(39)$ & $2(22)$ & .02 \\
\hline Oral medication (\%) & $456(54)$ & $159(55)$ & $190(52)$ & $92(53)$ & $4(44)$ & .79 \\
\hline \multicolumn{7}{|l|}{ Coronary artery disease } \\
\hline One vessel (\%) & $537(8)$ & $186(10)$ & $264(8)$ & $62(4)$ & $3(5)$ & $\leq .001$ \\
\hline Two vessel (\%) & $1547(23)$ & $497(26)$ & $741(23)$ & $257(18)$ & $7(11)$ & \\
\hline Three vessel (\%) & $3410(51)$ & $919(49)$ & $1641(51)$ & $750(54)$ & $38(59)$ & \\
\hline Left main stenosis (\%) & $1180(18)$ & $282(15)$ & $548(17)$ & $314(23)$ & $15(23)$ & \\
\hline \multicolumn{7}{|l|}{ Left ventricular function } \\
\hline Normal (\%) & $2757(41)$ & $793(42)$ & $1348(42)$ & $554(40)$ & $13(20)$ & $\leq .001$ \\
\hline Reduced $(\%)$ & $2460(37)$ & $676(36)$ & $1200(37)$ & $514(37)$ & $26(41)$ & \\
\hline Missing (\%) & 1114 (17) & $333(18)$ & 499 (16) & $211(15)$ & $17(27)$ & \\
\hline \multicolumn{7}{|l|}{ Postoperative morbidity } \\
\hline Early bleeding (\%) & $257(4)$ & $50(3)$ & $117(4)$ & $80(6)$ & $6(9)$ & $\leq .001$ \\
\hline Mediastinitis (\%) & $58(1)$ & $15(1)$ & $27(1)$ & $14(1)$ & $1(2)$ & .85 \\
\hline
\end{tabular}

$B M I$, Body mass index; $M I$, myocardial infarction, *Includes $156(2 \%)$ patients without data on serum creatinine concentrations.

1989, and 1990 through 1995. In multivariate analyses year of operation was treated as a continuous variable. The sensitivity and specificity of serum creatinine concentration and calculated $\mathrm{Ccr}$, respectively, for the identification of early deaths after CABG were analyzed by receiver operating characteristic (ROC) curves. In these analyses serum creatinine concentration and Ccr were entered as continuous variables in the interval of 50 to 200 (serum creatinine concentration) and 25 to 150 (Ccr). Because of small numbers, patients outside these intervals were grouped into one category. The areas under the ROC curves were calculated and compared with nonparametric methods by Mann-Whitney statistics together with a $\chi^{2}$ test for the differences in areas under the curves.

SAS statistical software, version 8.2 (SAS Institute, Inc, Cary, NC), was used for all analyses.

\section{Results}

Patient Characteristics

There were 1262 (19\%) women and $5449(81 \%)$ men in the study (Table E1). Normal renal function was present in $28 \%$ of the patients. Forty-eight percent had mild RI, and $21 \%$ had moderate RI. Severely reduced renal function with a Ccr of less than $30 \mathrm{~mL} / \mathrm{min}$ was present in $2 \%$ of women and $1 \%$ of men.

With increasing degree of RI, the patients were older and more likely to have hypertension, a history of MI or a previous stroke, peripheral vascular disease, left main coronary artery stenosis, unstable angina, lower BMI, and a severely reduced LVF (Table 1). Diabetes mellitus was not more common in patients with RI.

\section{Outcome}

There were 136 (2.0\%) early deaths in total. Among 6555 patients with data on Ccr, there were 129 (2.0\%) deaths. The crude risk of early death increased both in men and women with decreasing $\mathrm{Ccr}$ (Figure E1). In patients with severe and moderate RI, early mortality was $10.9 \%$ and $4.2 \%$, respectively, compared with $0.7 \%$ in patients with normal renal 
TABLE 2. Early mortality after coronary artery bypass grafting from 1980 through 1995 in relation to sex and preoperative creatinine clearance

\begin{tabular}{|c|c|c|c|c|c|c|c|}
\hline & \multicolumn{7}{|c|}{ Creatinine clearance $(\mathrm{mL} / \mathrm{min})$} \\
\hline & \multirow{2}{*}{$\begin{array}{l}\geq 90 \\
\text { OR }\end{array}$} & \multicolumn{2}{|c|}{$60-90$} & \multicolumn{2}{|c|}{$30-60$} & \multicolumn{2}{|c|}{$<30$} \\
\hline & & OR & $95 \% \mathrm{CI}$ & OR & $95 \% \mathrm{Cl}$ & OR & $95 \% \mathrm{Cl}$ \\
\hline Men & $\begin{array}{c}n=1715 \\
12 \text { deaths }(0.7 \%)\end{array}$ & \multicolumn{2}{|c|}{$\begin{array}{c}\mathrm{n}=2661 \\
39 \text { deaths }(1.5 \%)\end{array}$} & \multicolumn{2}{|c|}{$\begin{array}{c}\mathrm{n}=906 \\
42 \text { deaths }(4.6 \%)\end{array}$} & \multicolumn{2}{|c|}{$\begin{array}{c}\mathrm{n}=41 \\
4 \text { deaths }(9.8 \%)\end{array}$} \\
\hline Crude & 1.0 & 2.1 & $1.1-4.0$ & 6.9 & $3.6-13.2$ & 15.3 & $4.7-49.8$ \\
\hline Adjusted for age & 1.0 & 1.3 & $0.6-2.5$ & 2.7 & $1.3-5.9$ & 5.1 & 1.4-18.6 \\
\hline Multivariate adjustment* & 1.0 & 1.3 & $0.6-2.6$ & 2.8 & $1.3-6.0$ & 5.0 & $1.3-18.5$ \\
\hline Women & $\begin{array}{c}n=173 \\
1 \text { death }(0.6 \%)\end{array}$ & \multicolumn{2}{|c|}{$\begin{array}{c}\mathrm{n}=551 \\
12 \text { deaths }(2.2 \%)\end{array}$} & \multicolumn{2}{|c|}{$\begin{array}{c}\mathrm{n}=485 \\
16 \text { deaths }(3.3 \%)\end{array}$} & \multicolumn{2}{|c|}{$\begin{array}{c}\mathrm{n}=23 \\
3 \text { deaths }(13.0 \%)\end{array}$} \\
\hline Crude & 1.0 & 3.8 & $0.5-29.7$ & 5.9 & $0.8-44.6$ & 25.8 & $2.6-259.9$ \\
\hline Adjusted for age & 1.0 & 3.0 & $0.4-24.3$ & 3.9 & $0.5-32.0$ & 15.5 & $1.4-176.2$ \\
\hline Multivariate adjustment† & 1.0 & 3.1 & $0.4-24.1$ & 4.5 & $0.6-34.6$ & 15.4 & $1.5-164.1$ \\
\hline All patients & $\begin{array}{c}\mathrm{n}=1888 \\
13 \text { deaths }(0.7 \%)\end{array}$ & \multicolumn{2}{|c|}{$\begin{array}{c}n=3212 \\
51 \text { deaths }(1.6 \%)\end{array}$} & \multicolumn{2}{|c|}{$\begin{array}{c}n=1391 \\
58 \text { deaths }(4.2 \%)\end{array}$} & \multicolumn{2}{|c|}{$\begin{array}{c}\mathrm{n}=64 \\
7 \text { deaths }(10.9 \%)\end{array}$} \\
\hline Crude & 1.0 & 2.3 & $1.3-4.3$ & 6.3 & $3.4-11.5$ & 17.7 & $6.8-46.1$ \\
\hline Adjusted for age & 1.0 & 1.5 & $0.8-2.9$ & 2.8 & $1.4-5.7$ & 6.9 & $2.4-19.7$ \\
\hline Multivariate adjustment $\ddagger$ & 1.0 & 1.4 & $0.7-2.6$ & 2.4 & $1.2-4.8$ & 4.7 & $1.6-13.8$ \\
\hline
\end{tabular}

Odds ratios are calculated in relation to patients with a creatinine clearance of $90 \mathrm{~mL} / \mathrm{min}$ or greater. $O R$, Odds ratio; $C l$, confidence interval. $* A d j u s t e d$ for age, year of operation, diabetes mellitus, and left ventricular function. †Adjusted for previous myocardial infarction, peripheral vascular disease, and left ventricular function. $\ddagger$ Adjusted for age, year of operation, peripheral vascular disease, diabetes mellitus, and left ventricular function.

function (Table 2). Calculated Ccr remained a strong predictor of early mortality after multivariate adjustment for age, year of operation, previous MI, diabetes mellitus, peripheral vascular disease, and LVF. In patients with severe RI, the risk of early death was significantly higher (OR, 4.8; 95\% confidence interval [CI], 1.6-13.9) than in patients with normal renal function. Similarly, the risk of early mortality was higher (OR, 2.4; 95\% CI, 1.2-4.8) in patients with moderate RI than in those with normal renal function.

Only 3 women (13.0\%) with severe RI and 16 women (3.3\%) with moderate RI died within 30 days of the operation. The point estimates suggested an increased early mortality of approximately the same order as in men. Similarly, after multivariate adjustment, there was a continuous increase of OR for early death associated with decreasing Ccr (Figure E2).

The area under the ROC curve for Ccr and serum creatinine concentration was 0.71 and 0.62 , respectively, yielding a difference of $0.08(P=.0004)$. This significantly greater area for Ccr compared with serum creatinine concentration is shown in Figure 1.

No increased risk of mediastinitis or reoperation for bleeding was observed in patients with RI (Tables 3 and 4).

In $17 \%(n=1114)$ of the patients, information on LVF was not available. Among these patients, most characteristics did not differ compared with patients with information on LVF. However, they were more likely to have unstable angina and multivessel disease but less likely to have a history of MI.

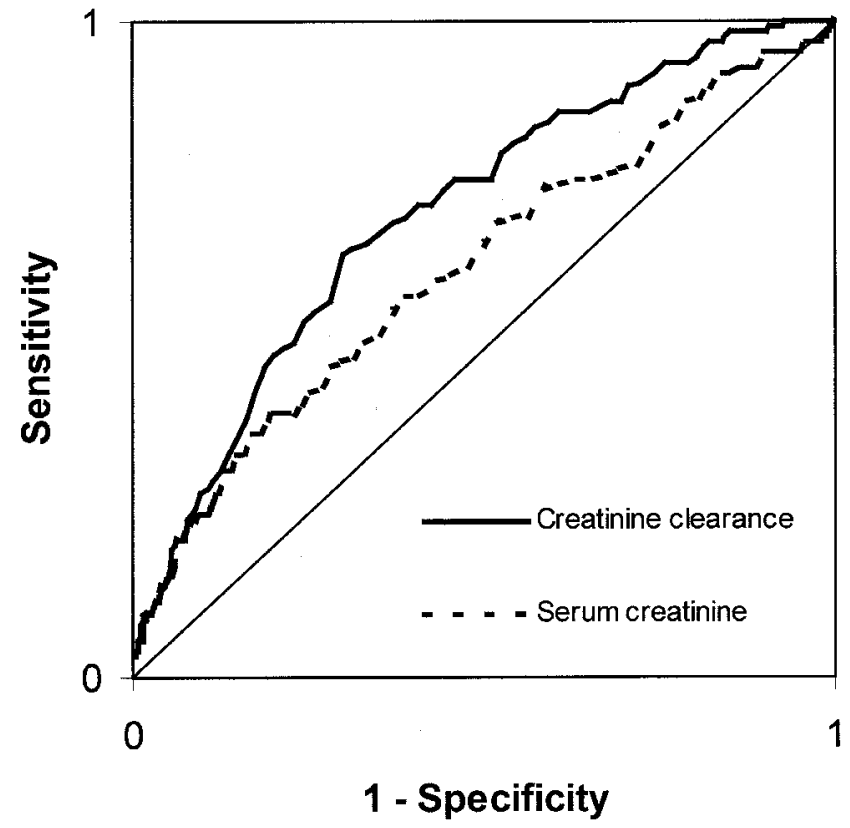

Figure 1. Receiver operating characteristic curves comparing calculated creatinine clearance and serum creatinine concentration as predictors of early mortality in 6555 patients undergoing coronary artery bypass surgery. 
TABLE 3. Early reoperation for bleeding in 6555 patients undergoing coronary artery bypass grafting from 1980 through 1995 in relation to preoperative creatinine clearance

\begin{tabular}{|c|c|c|c|c|c|c|c|}
\hline & \multicolumn{7}{|c|}{ Creatinine clearance $(\mathrm{mL} / \mathrm{min})$} \\
\hline & \multirow{2}{*}{$\begin{array}{l}\geq 90 \\
\text { OR }\end{array}$} & \multicolumn{2}{|c|}{$60-90$} & \multicolumn{2}{|c|}{$30-60$} & \multicolumn{2}{|c|}{$<30$} \\
\hline & & $\mathbf{O R}$ & $95 \% \mathrm{CI}$ & $\mathbf{O R}$ & $95 \% \mathrm{CI}$ & $\mathbf{O R}$ & $95 \% \mathrm{CI}$ \\
\hline All patients & $\begin{array}{c}\mathrm{n}=1888 \\
50 \text { bleedings }(2.6 \%)\end{array}$ & \multicolumn{2}{|c|}{$\begin{array}{c}\mathrm{n}=3212 \\
117 \text { bleedings (3.6\%) }\end{array}$} & \multicolumn{2}{|c|}{$\begin{array}{c}n=1391 \\
80 \text { bleedings }(5.8 \%)\end{array}$} & \multicolumn{2}{|c|}{$\begin{array}{c}n=64 \\
6 \text { bleedings }(9.4 \%)\end{array}$} \\
\hline Crude & 1.0 & 1.4 & $1.0-1.9$ & 2.2 & $1.6-3.2$ & 3.8 & $1.6-9.2$ \\
\hline Adjusted for age & 1.0 & 1.2 & $0.8-1.7$ & 1.7 & $1.1-2.7$ & 2.8 & 1.1-7.1 \\
\hline Multivariate adjustment ${ }^{*}$ & 1.0 & 0.9 & $0.6-1.3$ & 1.0 & $0.6-1.7$ & 1.4 & $0.5-3.9$ \\
\hline
\end{tabular}

Odds ratios are calculated in relation to patients with creatinine clearance of $90 \mathrm{~mL} /$ min or greater. $O R, O d d s$ ratio; $C l$, confidence interval. $* A d j u s t e d$ for age, sex, year of operation, body mass index, diabetes mellitus, and unstable angina.

In total, $2.6 \%(\mathrm{n}=29)$ had died within 30 days postoperatively among patients with missing information on LVF. Analyses of early mortality corresponding to those presented in Table 2, but without including the patients with missing information on LVF, provided lower estimates of the risk associated with a moderately (OR, 2.3; $95 \% \mathrm{CI}$, $1.0-5.1)$ and in particular severely reduced renal function (OR, 1.6; 95\% CI, 0.3-8.7). Among patients with a Ccr of less than $30 \mathrm{~mL} / \mathrm{min}$ without information on LVF, a particularly high early mortality was present (OR, 14.6; 95\% CI, 2.5-86.1) compared with that seen in subjects with normal renal function.

\section{Discussion}

A number of studies have identified impaired renal function as a predictor of mortality and morbidity in patients undergoing $\mathrm{CABG}$. Early studies focused on rather pronounced RI, ${ }^{17,18}$ but later studies have found that even mild RI is of prognostic importance..$^{9,11,12}$ Patients with RI have an increased risk of acute renal failure, bleeding, stroke, and prolonged ventilation, as well as prolonged stay in the intensive care unit or otherwise in the hospital postoperatively. Patients who have acute renal failure and require hemodialysis have a markedly increased rate of mortality. ${ }^{19}$

The glomerular filtration rate (GFR) is considered the best marker of renal function. Because the methods used to measure GFR are costly and not readily available, most often, GFR is estimated from serum creatinine concentrations. However, serum creatinine concentrations are affected by other factors than the filtration of creatinine, ${ }^{20}$ which is why several formulas have been developed to calculate Ccr. The most widely used formula is that of Cockcroft and Gault, ${ }^{15}$ which takes sex, age, and weight into consideration and is accurate even in patients with RI who have normal serum creatinine concentrations. ${ }^{13}$

Earlier studies published on the prognostic importance of non-dialysis-dependent RI in patients undergoing CABG have often used serum creatinine concentrations to define renal function. The definition of RI has commonly been a serum creatinine concentration of $1.5 \mathrm{mg} / \mathrm{dL}(133 \mu \mathrm{mol} / \mathrm{L})$ or more. ${ }^{9,10,12,21}$ However, a woman 70 years of age with a weight of $60 \mathrm{~kg}$ and a serum creatinine level of $1.4 \mathrm{mg} / \mathrm{dL}$ (124 $\mu \mathrm{mol} / \mathrm{L}$ ) would have a Ccr determined by using the formula of Cockroft and Gault of not more than $35 \mathrm{~mL} / \mathrm{min}$. Similarly, a man 75 years of age with a weight of $70 \mathrm{~kg}$ and

TABLE 4. Mediastinitis in 6555 patients undergoing coronary artery bypass grafting from 1980 through 1995 in relation to preoperative creatinine clearance

\begin{tabular}{|c|c|c|c|c|c|c|c|}
\hline & \multicolumn{7}{|c|}{ Creatinine clearance $(\mathrm{mL} / \mathrm{min})$} \\
\hline & \multirow{2}{*}{$\begin{array}{l}\geq 90 \\
\text { OR }\end{array}$} & \multicolumn{2}{|c|}{$60-90$} & \multicolumn{2}{|c|}{$30-60$} & \multicolumn{2}{|c|}{$<30$} \\
\hline & & $\mathbf{O R}$ & $95 \% \mathrm{Cl}$ & OR & $95 \% \mathrm{Cl}$ & $\mathbf{O R}$ & $95 \% \mathrm{Cl}$ \\
\hline All patients & $\begin{array}{c}n=1888 \\
15 \text { infections }(0.8 \%)\end{array}$ & \multicolumn{2}{|c|}{$\begin{array}{c}n=3212 \\
27 \text { infections }(0.8 \%)\end{array}$} & \multicolumn{2}{|c|}{$\begin{array}{c}n=1391 \\
14 \text { infections }(1.0 \%)\end{array}$} & \multicolumn{2}{|c|}{$\begin{array}{c}\mathrm{n}=64 \\
1 \text { infection }(1.6 \%)\end{array}$} \\
\hline Crude & 1.0 & 1.1 & $0.6-2.0$ & 1.3 & $0.6-2.6$ & 2.0 & $0.3-15.2$ \\
\hline Adjusted for age & 1.0 & 0.7 & $0.3-1.4$ & 0.6 & $0.2-1.4$ & 0.8 & $0.1-6.4$ \\
\hline Multivariate adjustment* & 1.0 & 1.0 & $0.5-2.1$ & 1.2 & $0.5-3.2$ & 1.9 & $0.2-16.4$ \\
\hline
\end{tabular}

Odds ratios are calculated in relation to patients with creatinine clearance of $90 \mathrm{~mL} / \mathrm{min}$ or greater.

$O R$, Odds ratio; $\mathrm{Cl}$, confidence interval. *Adjusted for age, sex, body mass index, and diabetes mellitus. 
a serum creatinine value of $1.4 \mathrm{mg} / \mathrm{dL}(124 \mu \mathrm{mol} / \mathrm{L})$ would have a Ccr of only $45 \mathrm{~mL} / \mathrm{min}$. Thus using serum creatinine concentrations to assess renal function might greatly overestimate GFR.

This might explain why mild RI in our study was not associated with early mortality as opposed to some earlier studies in which serum creatinine concentrations were used to define renal function. ${ }^{9,12}$ It is reasonable to believe that the degree of RI was underestimated in these studies and that several patients defined as having mild RI had moderate RI instead.

We defined renal function according to the guidelines published by the National Kidney Foundation. ${ }^{16}$ However, the large number of patients included also allowed us to divide the patients into 6 , instead of 4 , subgroups, according to renal function. By doing this, we found that the risk of early death seemed to increase continuously with decreasing Ccr.

Whether there is a threshold in which RI becomes a risk factor for early death after CABG still needs to be investigated. However, we believe that RI should be regarded as a continuous risk factor within each group of RI. There is a quite considerable difference in renal function between a patient with a Ccr of 30 to $35 \mathrm{~mL} / \mathrm{min}$ and one with a Ccr of 55 to $60 \mathrm{~mL} / \mathrm{min}$. Yet both of these patients are defined as having moderate RI. In clinical practice it might be appropriate to use more narrow intervals of Ccr than those proposed by the National Kidney Foundation to get a more accurate estimate of risk.

One of our objectives was to assess whether Ccr, as calculated by the Cockroft-Gault formula, is a better predictor of early mortality than serum creatinine concentration. ROC analyses indicated that Ccr was better in predicting early mortality than serum creatinine concentration. In patients in whom anthropometric data are known, we suggest that Ccr should be used instead of serum creatinine concentration to assess renal function.

RI becomes more common with increasing age. It is also present more often in patients with comorbidities associated with increased mortality and morbidity after CABG. However, in our study RI remained a strong predictor of early death, even after adjustment for several prognostic factors.

We used the Cockroft-Gault formula, in which age, sex, weight, and serum creatinine are included to calculate Ccr. All these variables are known to be associated independently with early mortality after CABG. This raises the question of whether there really is a biologic link between the kidney and its level of function and early mortality or if we simply have found a formula to predict early death without a necessary link to kidney function. Irrespective of which of these interpretations is true, from a practical point of view, Ccr seems to be a better predictor of early mortality than serum creatinine concentration.

Because of the relatively large number of women in our study, we were able to carry out sex-specific analyses. Our results suggested similar associations in women as in men, but there were too few deaths among women to show a statistically significant difference in early mortality related to Ccr.

\section{Limitations}

Our study was conducted at a single center, and it might well be that the results are not applicable to all other hospitals performing thoracic surgery. Some preoperative conditions known to be of prognostic importance as chronic obstructive pulmonary disease and priority of surgical intervention were not available to us and thus were not included in multivariate analyses. ${ }^{16,22,23}$ Other potentially prognostic factors not included were New York Heart Association functional class, use of an intra-aortic balloon pump, length of the operation, and crossclamp time. However, the number of obstructed coronary arteries was included, which is closely related to crossclamp time and length of the operation. In one earlier study crossclamp time was not related to early outcomes in patients with RI. ${ }^{12}$ An intra-aortic balloon pump was used rarely during this period of time. It is possible that failure to include certain preoperative conditions in the multivariate analyses resulted in some remaining confounding. In view of the strong association that we observed, it is unlikely that this severely influenced our findings. The postoperative complications available in our study were bleeding and mediastinitis. We do not know whether stroke, cardiac events, or acute renal failure requiring hemodialysis postoperatively were related to RI in our study population.

Our study population was younger and had less extensive coronary artery disease than what has been reported in other studies. ${ }^{24}$ It is likely that this will be of importance for the confounding effect of these factors in analyses of Ccr and early outcome. This makes any comparison of crude estimates of risk between centers difficult and calls for wellperformed multivariate analyses.

In $17 \%$ of our patients, information on LVF was not available. These patients were more likely to have unstable angina and multivessel disease. Some of these patients underwent emergency operations and did not undergo ventriculography. In multivariate analyses we included patients without information on LVF to retain information on the association between renal function and early outcomes. We also performed multivariate analyses without including these patients, but in these analyses the association between RI and early mortality tended to be lower. RI was more common in the group in which LVF was missing, thus explaining this underestimation. 
Our study was not designed to answer questions about how to manage patients with RI undergoing CABG. However, in one recent study, perioperative dialysis in patients with rather pronounced non-dialysis-dependent RI undergoing CABG (serum creatinine $\geq 2.5 \mathrm{mg} / \mathrm{dL}[222 \mu \mathrm{mol} / \mathrm{L}]$ ) showed decreased postoperative mortality and morbidity. ${ }^{25}$ Other studies have suggested that off-pump CABG offers renal protection and decreases postoperative morbidity and acute renal failure in patients with RI. ${ }^{26}$

\section{Conclusions}

Patients with moderate and severe RI have increased risk of early mortality after undergoing a first isolated CABG, even after adjusting for other known risk factors. We suggest that all patients scheduled to undergo CABG should have their renal function carefully assessed by using Ccr instead of serum creatinine concentrations to better determine the risk of early death postoperatively.

We thank Christian Unge, Henrik Overödder, and Björn Törnkvist for collecting information from the medical records.

\section{References}

1. Hall WD. Abnormalities of kidney function as a cause and a consequence of cardiovascular disease. Am J Med Sci. 1999;317:176-82.

2. Foley RN, Parfrey PS, Sarnak MJ. Clinical epidemiology of cardiovascular disease in chronic renal disease. Am J Kidney Dis. 1998; 32(suppl):S112-9.

3. Mann JF, Gerstein HC, Pogue J, Bosch J, Yusuf S. Renal insufficiency as a predictor of cardiovascular outcomes and the impact of ramipril: the HOPE randomized trial. Ann Intern Med. 2001;134:629-36.

4. Wright RS, Reeder GS, Herzog CA, Albright RC, Williams BA, Dvorak DL, et al. Acute myocardial infarction and renal dysfunction: a high-risk combination. Ann Intern Med. 2002;137:563-70.

5. Shlipak MG, Heidenreich PA, Noguchi H, Chertow GM, Browner WS, McClellan MB, et al. Association of renal insufficiency with treatment and outcomes after myocardial infarction in elderly patients. Ann Intern Med. 2002;137:555-62.

6. Liu JY, Birkmeyer NJ, Sanders JH, Morton JR, Henriques HF, Lahey SJ, et al. Risks of morbidity and mortality in dialysis patients undergoing coronary artery bypass surgery. Northern New England Cardiovascular Disease Study Group. Circulation. 2000;102:2973-7.

7. Herzog CA, Ma JZ, Collins AJ. Poor long-term survival after acute myocardial infarction among patients on long-term dialysis. $N \mathrm{Engl}$ J Med. 1998;339:799-805.

8. Zamora JL, Burdine JT, Karlberg H, Shenaq SM, Noon GP. Cardiac surgery in patients with end-stage renal disease. Ann Thorac Surg. 1986;42:113-7.

9. Anderson RJ, O'Brien M, Mawhinney S, Villanueva CB, Moritz TE, Sethi GK, et al. Renal failure predisposes patients to adverse outcome after coronary artery bypass surgery. VA Cooperative Study \#5. Kidney Int. 1999;55:1057-62.

10. Nakayama Y, Sakata R, Ura M, Itoh T. Long-term results of coronary artery bypass grafting in patients with renal insufficiency. Ann Thorac Surg. 2003;75:496-500.

11. Weerasinghe A, Hornick P, Smith P, Taylor K, Ratnatunga C. Coronary artery bypass grafting in non-dialysis-dependent mild-to- moderate renal dysfunction. J Thorac Cardiovasc Surg. 2001;121:1083-9.

12. Durmaz I, Büket S, Atay Y, Yagdi T, Ozbaran M, Boga M, et al. Cardiac surgery with cardiopulmonary bypass in patients with chronic renal failure. J Thorac Cardiovasc Surg. 1999;118:306-15.

13. Bostom AG, Kronenberg F, Ritz E. Predictive performance of renal function equations for patients with chronic kidney disease and normal serum creatinine levels. J Am Soc Nephrol. 2002;13:2140-4.

14. Bartels H, Böhmer M, Heierli C. Serum creatinine determination without protein precipitation [in German]. Clin Chim Acta. 1972;37: 193-7.

15. Cockcroft DW, Gault MH. Prediction of creatinine clearance from serum creatinine. Nephron. 1976;16:31-41.

16. National Kidney Foundation. K/DOQI clinical practice guidelines for chronic kidney disease: evaluation, classification and stratification. Am J Kidney Dis 2002;39(Suppl 2)S1-S246.

17. Higgins TL, Estafanous FG, Loop FD, Beck GJ, Blum JM, Paranandi L. Stratification of morbidity and mortality outcome by preoperative risk factors in coronary artery bypass patients. A clinical severity score. JAMA. 1992;267:2344-8.

18. O'Connor GT, Plume SK, Olmstead EM, Coffin LH, Morton JR, Maloney CT, et al. Multivariate prediction of in-hospital mortality associated with coronary artery bypass graft surgery. Northern New England Cardiovascular Disease Study Group. Circulation. 1992;85: 2110-8.

19. Chertow GM, Lazarus JM, Christiansen CL, Cook EF, Hammermeister KE, Grover F, et al. Preoperative renal risk stratification. Circulation. 1997;95:878-84.

20. Levey AS. Measurement of renal function in chronic renal disease. Kidney Int. 1990;38:167-84.

21. Szczech LA, Best PJ, Crowley E, Brooks MM, Berger PB, Bittner V, et al. Outcomes of patients with chronic renal insufficiency in the bypass angioplasty revascularization investigation. Circulation. 2002; 105:2253-8.

22. Jones RH, Hannan EL, Hammermeister KE, Delong ER, O'Connor GT, Luepker RV, et al. Identification of preoperative variables needed for risk adjustment of short-term mortality after coronary artery bypass graft surgery. The Working Group Panel on the Cooperative CABG Database Project. J Am Coll Cardiol. 1996;28:1478-87.

23. Kurki TS, Kataja M. Preoperative prediction of postoperative morbidity in coronary artery bypass grafting. Ann Thorac Surg. 1996;61: 1740-5.

24. Peterson ED, Coombs LP, DeLong ER, Haan CK, Ferguson TB. Procedural volume as a marker of quality for CABG surgery. JAMA. 2004;291:195-201.

25. Durmaz I, Yagdi T, Calkavur T, Mahmudov R, Apayadin AZ, Posacioglu H, et al. Prophylactic dialysis in patients with renal dysfunction undergoing on-pump coronary artery bypass surgery. Ann Thorac Surg. 2003;75:859-64.

26. Ascione R, Lloyd CT, Gomes WJ, Caputo M, Bryan AJ, Angelini GD. On-pump versus off-pump coronary revascularization: evaluation of renal function. Ann Thorac Surg. 1999;68:493-8. 
TABLE E1. Preoperative creatinine clearance in patients undergoing coronary artery bypass surgery in relation to sex

\begin{tabular}{|c|c|c|c|c|c|c|}
\hline \multirow[b]{2}{*}{ Creatinine clearance $(\mathrm{mL} / \mathrm{min})$} & \multicolumn{2}{|c|}{ Men } & \multicolumn{2}{|c|}{ Women } & \multicolumn{2}{|c|}{ Total } \\
\hline & $\mathbf{n}$ & $\%$ & $\mathbf{n}$ & $\%$ & $\mathbf{n}$ & $\%$ \\
\hline Missing value & 126 & 2 & 30 & 2 & 156 & 2 \\
\hline$\geq 90$ & 1715 & 31 & 173 & 14 & 1888 & 28 \\
\hline $60-90$ & 2661 & 49 & 551 & 44 & 3212 & 48 \\
\hline $30-60$ & 906 & 17 & 485 & 38 & 1391 & 21 \\
\hline$<30$ & 41 & 1 & 23 & 2 & 64 & 1 \\
\hline Total & 5449 & 100 & 1262 & 100 & 6711 & 100 \\
\hline
\end{tabular}

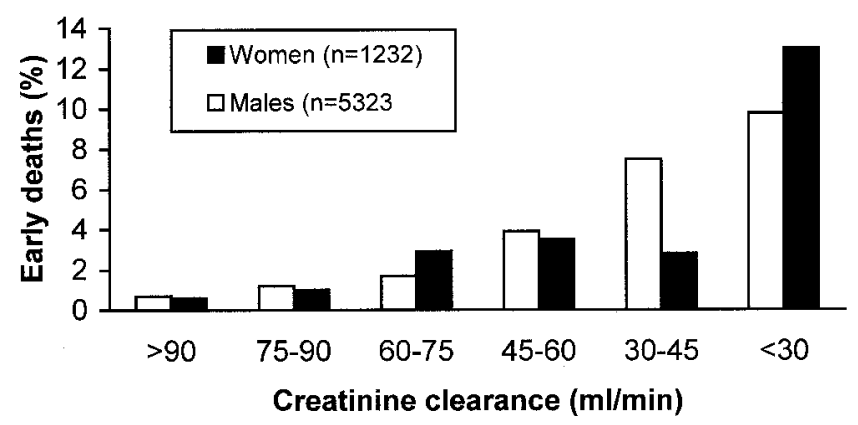

Figure E1. Early death in relation to sex and creatinine clearance in 6555 patients undergoing coronary artery bypass grafting.

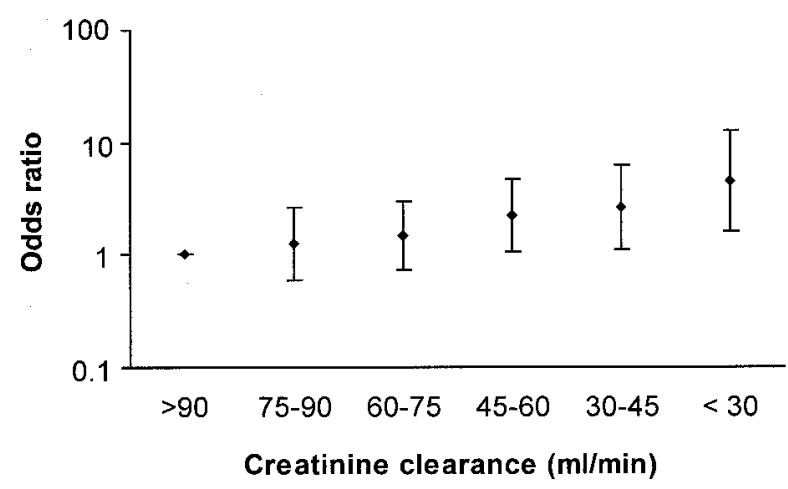

Figure E2. Odds ratios for the risk of early death in 6555 patients related to creatinine clearance. Patients with creatinine clearance of $90 \mathrm{~mL} / \mathrm{min}$ or greater were used as a reference group. Adjustment was made for age, year of operation, previous myocardial infarction, diabetes mellitus, peripheral vascular disease, and left ventricular function. 